\title{
ANÁlISIS DE LA CONSTITUCIÓN ECONÓMICA NICARAGÜENSE CON ESPECIAL REFERENCIA A LA LIBERTAD DE EMPRESA
}

\author{
Jesús Jusseth HERRERA ESPINOZA \\ Profesor Adjunto de Derecho Mercantil \\ Universidad Centroamericana
}

\section{Introducción a la constitución económica en general}

$\mathrm{N}$ o cabe duda de que uno de los signos de identidad del Derecho Constitucional actual es la "constitucionalización de los principios reguladores de la economía”. Es más, se suele afirmar con frecuencia que el sistema económico, junto con el territorio, la población y el gobierno, está firmemente asociado a la noción misma del Estado contemporáneo, debiendo tenerse en cuenta, necesariamente, el elemento económico para concebir a aquél como tal, es decir, como Estado ${ }^{1}$.

En otras palabras, las Constituciones postmodernas formulan jurídicamente, además de su contenido político, una Constitución Económica a los efectos de ordenar las grandes líneas de dicha actividad, bien que ésta vaya a ser desarrollada por los particulares, bien que lo sea por el sector público².

De hecho, es en el siglo XIX, en Alemania, donde se formula por primera vez el concepto de Constitución Económica (Wirtschaftsverfassung), aunque, eso sí, inicialmente se trata de un concepto referido sólo al ámbito económico. Éste hacía alusión al fundamento, la estructura, la ordenación, la base misma del sistema económico, es decir, los principios y reglas esenciales por los que se rige.

Posteriormente, al reconocer la Constitución de Weimar los denominados derechos sociales y económicos, se sentaron las bases para la juridificación del término "Constitución Económica", dotándolo, en consecuencia, de un significado distinto al originalmente esbozado. Ya en 1932 la doctrina alemana concebía la Constitución económica como ordenación de la propiedad, del contrato y del trabajo, de la forma y extensión de la intervención del Estado, así como de la organización y la técnica de la producción y distribución. De hecho, la expresión Constitución Económica provocó cierta resistencia por parte de los juristas del Derecho Público, para los que se trataba, ya sea de un concepto impreciso y abe-

1 BREWER-CARÍAS, Allan R., "Reflexiones sobre la constitución económica" en Estudios sobre la Constitución Española. Homenaje al Profesor Eduardo García de Enterría, Tomo V, coordinación y presentación por Sebastián Martín-Retortillo, Civitas, Madrid, 1991, pág. 3840.

2 BREWER-CARÍAS, Allan R., op. cit., ibidem. 
rrante, o bien, en cuanto pieza de la constitución del Estado, no pasaba de ser un supuesto básico ideal ${ }^{3}$.

Aunque no hay unanimidad en lo atinente al contenido concreto del concepto, en términos muy generales la Constitución Económica (misma que se integra y forma parte del concepto, también jurídico, de Constitución Política) es la expresión del marco y de los principios jurídicos de la Ley fundamental que ordenan y regulan la estructura y funcionamiento de la actividad económica ${ }^{4}$.

La Constitución Económica se concibe, pues, como un subsistema del propio sistema constitucional, que establece y consagra las normas fundamentales por las que debe regirse la ordenación de la actividad económica. Más concretamente, el Derecho Constitucional Económico es el conjunto de normas constitucionales que estatuyen los principios ordenadores de la actividad económica que llevan a cabo los Poderes Públicos y los operadores económicos privados $^{5}$.

En tal sentido conviene tener presente, como punto de referencia, el quehacer del Tribunal Constitucional español que nos ofrece una útil noción de Constitución Económica, en cuanto considera que ésta "designa el marco jurídico fundamental para la estructura y funcionamiento de la actividad económica o, dicho sea de otro modo, para el orden del proceso económico. En ella se definen el orden económico y sus fundamentos esenciales, y se establecen normas que sirvan de parámetros para la acción de los operadores económicos. Asi entendida, la Constitución Económica contenida en la Constitución Política no garantiza necesariamente un sistema económico ni lo sanciona. Permite el funcionamiento de todos los sistemas que se ajustan a los parámetros y sólo excluye aquellos que sean contradictorios con los mismos"'.

Además, no debe perderse de vista que el mismo tribunal ha declarado que "en la Constitución española de 1978, a diferencia de lo que solía ocurrir con las Constituciones liberales del siglo XIX, y de forma semejante a lo que sucede en las más recientes Constituciones europeas, existen varias normas destinadas a proporcionar el marco jurídico fundamental para la estructura y funcionamiento de la actividad económica; el conjunto de todas ellas compone lo que suele denominarse la Constitución Económica formal. Este marco implica la existencia de unos principios básicos del orden económico que han de aplicarse con carácter unitario, unicidad

3 DE LOJENDIO, Ignacio María, "Derecho Constitucional Económico" en Constitución y Economía. La Ordenación del Sistema Económico en las Constituciones Occidentales, coordinado por Luis Sánchez Agesta, Editorial Revista de Derecho Privado - Editoriales de Derecho Reunidas, Madrid, 1977, págs. 82 y s.

4 GARCÍA-PELAYO, Manuel, “Consideraciones sobre las cláusulas económicas de la Constitución” en Estudios sobre la Constitución española de 1978, edición preparada por Manuel Ramírez, Libros Pórtico, Zaragoza, 1979, pág. 31.

5 MARTíN-RETORTILlo, Sebastián, Derecho Administrativo Económico, Tomo I, La Ley, Madrid, 1991 (reimpresión), pág. 28.

6 Voto particular de la Sentencia del Tribunal Constitucional 37/1981, de 16 de noviembre (RTC 1981 \37). 
ésta reiteradamente exigida por la Constitución, cuyo Preámbulo garantiza la existencia de "un orden económico y social justo"7.

\section{La constitución económica nicaragüense}

Aterrizando en nuestra realidad patria, el Constituyente Nicaragüense tampoco ha podido escapar a la tendencia de dejar sentadas las grandes pautas que configuran el sistema económico que ha de imperar en el Estado de Nicaragua.

En tal sentido nuestra Carta Magna, desde su preámbulo, declara sin tapujos una velada intención por lograr "una nueva sociedad que elimine toda clase de explotación y logre la igualdad económica" de los nicaragüenses; erigiéndose éste en uno de los principios fundamentales que conforman el modelo específico de "Estado Social de Derecho" que es la nación nicaragüense ${ }^{8}$.

Esta declaración inicial se irá materializando, a lo largo del articulado de la Constitución, en distintos preceptos que reconocen, entre otras cosas, "las distintas formas de propiedad" " pública, privada, asociativa, cooperativa y comunitaria, mismas que deberán ser garantizadas y estimuladas sin discriminación para producir riquezas, y todas ellas dentro de su libre funcionamiento deberán cumplir una función social ${ }^{10}$.

Asimismo, se garantiza el derecho de propiedad privada de los bienes muebles e inmuebles, $y$ de los instrumentos y medios de producción. No sin antes advertir que en virtud de la función social de la propiedad, este derecho está sujeto, por causa de utilidad pública o de interés social, a las limitaciones y obligaciones que en cuanto a su ejercicio le impongan las leyes. Los bienes inmuebles pueden ser objeto de expropiación de acuerdo a la ley, previo pago en efectivo de justa indemnización ${ }^{11}$.

Lo anterior se completa con la pertinente aclaración de que tratándose de la expropiación de latifundios incultivados para fines de reforma agraria, la ley determinará la forma, cuantificación, plazos de pagos e intereses que se reconozcan en concepto de indemnización ${ }^{12}$. Sin perjuicio de que, como no podía ser de otra forma, se probibe la confiscación de bienes; respondiendo los funcionarios, en caso de infracción de dicho precepto, con sus bienes presentes y futuros por los daños inferidos al confiscado ${ }^{13}$.

Además de tutelar el Derecho de Propiedad, el Constituyente ha dejado patente que la función principal del Estado en la economia es desarrollar materialmente el país; supri-

\footnotetext{
Sentencia del Tribunal Constitucional 1/1982, de 28 de enero (RTC 1982 1 1). En el mismo sentido véase Sentencia del Tribunal Constitucional 11/1984, de 2 de febrero (RTC 1984\11).

8 Véase artículo $130 \mathrm{Cn}$.

9 Artículo $5 \mathrm{Cn}$.

10 Párrafo 4 del artículo $5 \mathrm{Cn}$.

11 Párrafos 1 y 2 del artículo $44 \mathrm{Cn}$.

12 Párrafo 3 del artículo $44 \mathrm{Cn}$.

13 Párrafo 3 del artículo $44 \mathrm{Cn}$.
} 
mir el atraso y la dependencia heredados; mejorar las condiciones de vida del pueblo y realizar una distribución cada vez más justa de la riqueza ${ }^{14}$.

En ese mismo orden de ideas, el Estado es responsable de promover el desarrollo integral del país, y como gestor del bien común deberá garantizar los intereses y las necesidades particulares, sociales, sectoriales y regionales de la nación. De tal forma que, es responsabilidad del Estado proteger, fomentar y promover las formas de propiedad y de gestión económica $y$ empresarial privada, estatal, cooperativa, asociativa, comunitaria y mixta, para garantizar la democracia económica y social ${ }^{15}$.

Como habrá podido inferir el lector atento, es posible afirmar que las disposiciones económicas contenidas en la Constitución nicaragüense no establecen un paradigma económico específico, sino que, antes bien, adoptan un modelo económico genérico que descarta, de un lado, la absoluta libertad económica, pese a que declara abiertamente que el "ejercicio de las actividades económicas corresponde primordialmente a los particulares"16, y, de otro, la estatalización absoluta de la economía ${ }^{17}$.

La anterior afirmación no constituye óbice para poder afirmar que uno de los preceptos claves en el sistema de normas que configuran la Constitución Económica Nicaragüense es el que consagra "la libertad de la empresa". Ello obedece a que tal declaración configura el sistema con perfiles muy definidos, a pesar de las dificultades que, en atención a su indeterminación, conlleva su puesta en práctica ${ }^{18}$. Del estudio en profundidad de dicho precepto Constitucional nos ocuparemos en los siguientes acápites.

\section{Libertad de empresa}

El párrafo cuarto del artículo 99, del Título VI (Economía Nacional, Reforma Agraria y Finanzas Públicas), Capítulo I (Economía Nacional), de la Constitu-

14 Artículo $98 \mathrm{Cn}$.

5 Artículo $99 \mathrm{Cn}$.

16 Primera parte del párrafo segundo del artículo 99 Cn., el cual sigue diciendo que "se reconoce el rol protagónico de la iniciativa privada, la cual comprende en un sentido amplio, a grandes, medianas y pequeñas empresas, micro empresas, empresas cooperativas, asociativas y otras".

17 En la misma línea de pensamiento véase, en Derecho comparado, ARAGÓN REYES, Manuel, Libertades Económicas y Estado Social, McGraw-Hill, Madrid, 1995, págs. 7 y ss.

En este sentido también resulta ilustrativa la alusión que hace el Texto Constitucional a la "economía mixta", bajo la idea de que las distintas formas de propiedad (pública, privada, cooperativa, asociativa y comunitaria), cuya coexistencia garantiza el Estado, "forman parte" de aquélla y, además, "están supeditadas a los intereses superiores de la nación y cumplen una función social".

18 No resulta baladí la opinión del Tribunal Constitucional español en este sentido, puesto que éste estima que el artículo 38 de la Constitución española "en cuanto reconoce la libertad de empresa en el marco de la economía de mercado viene a establecer los límites dentro de los que necesariamente han de moverse los poderes constituidos al adoptar medidas que incidan sobre el sistema económico de nuestra sociedad"; "tal precepto se encuentra en muy directa conexión con otros de la misma Constitución y, señaladamente, con el 128 y 131, en conexión con los cuales debe ser interpretado". 
ción Política "garantiza la libertad de empresa y el establecimiento de bancos y otras instituciones financieras, privadas y estatales que se regirán conforme las leyes de la materia".

A lo señalado por esta norma habrá que añadirle la declaración final del párrafo primero del artículo $104 \mathrm{Cn}$. que expresa abiertamente que la iniciativa económica es libre" ${ }^{19}$. Garantizándose, además, en el segundo párrafo del mismo artículo, "el pleno ejercicio de las actividades económicas, sin más limitaciones que (sic.) por motivos sociales o de interés nacional impongan las leyes" ${ }^{20}$.

Lo primero que salta a la vista, a la luz de lo señalado por los aludidos preceptos, es que, al menos por lo que atañe al artículo 99, el reconocimiento de la libertad de empresa se formula de manera contundente y más o menos precisa, en virtud de lo cual no es necesario su inferencia de conceptos conexos como sucede en otros ordenamientos.

En segundo lugar, la enunciación de la "libertad de empresa" sustituye la clásica nomenclatura del constitucionalismo tradicional, patrio y comparado, que se refería simplemente a la Libertad de Industria y Comercio. Tal transformación es relevante por cuanto la afirmación de la libertad de industria y comercio, a la luz de la historia, remite a una representación ideológica superada (la expresión de una reacción frente al orden económico corporativo del Antiguo Régimen y como pretensión de la gestión de la economía como un modo privativo de los particulares, e infranqueable por el Estado) y a una realidad económica transformada (debido a que hoy en día la actividad económica se centra más en la producción masiva de bienes y servicios que en la simple idea de cambio de mercancía a la que parece vinculada la expresión tradicional de "comercio e industria") ${ }^{21}$.

En tercer lugar, el reconocimiento de la "libertad de empresa" se "reafirma" a través de una especie de reelaboración manifestada a través de frases (tales como "la iniciativa económica es libre" o "se garantiza el pleno ejercicio de las actividades económicas”), que nada de sustancial añaden al precepto consagrado por el artículo 99.

19 Declaración que es corolario de lo prescrito por la primera parte de dicha norma, la cual reza que "las empresas que se organicen bajo cualesquiera de las formas de propiedad establecidas en esta Constitución, gozan de igualdad ante la ley y las políticas económicas del Estado".

20 Aún más, a todas esas declaraciones es posible agregar las del Artículo 105.1 y 3, que respectivamente señalan que: "Es obligación del Estado promover, facilitar y regular la prestación de los servicios públicos básicos de energía, comunicación, agua, transportes, infraestructura vial, puertos y aeropuertos a la población, y es derecho inalienable de la misma el acceso a ellos. Las inversiones privadas y sus modalidades y las concesiones de explotación a sujetos privados en estas áreas, serán reguladas por la ley en cada caso." Asimismo, "se garantiza el derecho de establecer servicios privados en las áreas de salud y educación".

${ }^{21}$ BASSOLS COMA, Martín, agrega que, por otro lado, esta actualización conceptual nos introduce en uno de los conceptos jurídicos de más difícil precisión y uso polivalente que existen en el lenguaje jurídico: la empresa: (Constitución y Sistema Económico, segunda edición, Tecnos, Madrid, 1988, págs. 109 y ss. 
Finalmente, el constituyente fija como límites -vale decir naturales- al ejercicio de la libertad de empresa, de una parte, los motivos sociales y, de otra, los motivos de interés nacional que impongan las leyes.

Ahora bien, atendiendo sólo al expediente de su ubicación "topográfica", y a diferencia de lo que sucede en otros ordenamientos jurídicos, la libertad de empresa no fue considerada por nuestra Carta Magna como un derecho fundamental, aun cuando su naturaleza ontológica corresponda a la propia de ese tipo de derechos.

Con todo, y apoyándonos en esta última afirmación, hemos optado, para proceder al análisis jurídico del precepto, por auxiliarnos, en gran medida, del marco teórico conceptual, que respecto de los derechos fundamentales como categoría jurídica, ha ofrecido el profesor Escobar Roca en un reciente trabajo ${ }^{22}$.

\subsection{Sujetos}

Los sujetos titulares del Derecho de Libertad de Empresa son, en principio, todas las personas físicas y jurídicas. No obstante, partiendo de esta afirmación general, habrá que descender al examen de determinadas categorías especiales de personas con el afán de comprobar en cada caso concreto las limitaciones en el ejercicio o, en su caso, la falta de titularidad del derecho en cuestión.

Entre estas categorías destacan los menores, los extranjeros, los funcionarios, militares, reclusos, determinados tipos de personas jurídicas (particularmente algunas personas jurídico-públicas ${ }^{23}$.

Necesariamente, para la determinación de los sujetos titulares del Derecho que nos ocupa, debemos partir de lo prescrito en el artículo 6 del Código de Comercio, el cual establece el concepto legal de comerciante individual (o más correctamente empresario individual), entendiéndose por éstos "los que se ocupan ordinaria y profesionalmente en alguna o algunas de las operaciones que corresponden a esta industria".

Sin embargo, a estos requisitos parece lógico añadir el de la capacidad legal es decir la facultad de gozar de capacidad civil plena, concretándose tal requisito en la satisfacción, por parte del calificado como comerciante, de dos exigencias establecidas en el artículo 278 del Código Civil: ser mayor de edad y tener la libre disposición de sus bienes.

22 El trabajo en cuestión, como el mismo declara a limine, "pretende ofrecer una síntesis de los conceptos básicos de una Parte General de los derechos fundamentales adaptada a la Constitución española de 1978": ESCOBAR ROCA, Guillermo, "Derechos Fundamentales: Una aproximación General" en Anuario de la Facultad de Derecho de Alcalá de Henares. Curso 1998-1999, número extraordinario en homenaje al Prof. Don Luis García San Miguel, Volumen VIII, Universidad de Alcalá de Henares, Alcalá de Henares, 2000, págs. 127 y ss.

${ }^{23}$ Cfr. ESCOBAR ROCA, op. cit., pág. 143. 
Con arreglo a la opinión generalizada, en el estado actual de la Legislación Civil ambas exigencias se encuentran estrechamente concatenadas -salvo excepciones dispuestas en normas imperativas-. De modo que, el artículo 278 del Código Civil prescribe la edad de 21 años cumplidos para atribuir la mayoría de edad, a la vez que el mismo artículo, deja sentado que el mayor de edad es capaz para todos los actos de la vida civil y, entre ellos, la disposición de sus bienes sin restricción alguna. En consecuencia, toda persona mayor de 21 años, no declarada incapaz, puede satisfacer, al menos a priori, los requisitos impuestos por el Código de Comercio para ser calificado como comerciante, en tanto que resulta ser simultáneamente mayor de edad y poseedor de la libre disposición de sus bienes. Lo que, en clave negativa, significa que los menores, en principio, no pueden ser comerciantes $^{24}$.

No obstante, el artículo 7 Cc. prescribe, de forma un poco enrevesada por cierto, que cuando los hijos de familia y menores adquieran bienes por letras o artes liberales, trabajo o industria y se dediquen al comercio: quedarán obligados solamente basta concurrencia de aquellos bienes; pero podrán enajenar o hipotecar sus bienes inmuebles para el cumplimiento de sus obligaciones mercantiles sin las formalidades prescritas por el mismo Código: y comparecer en juicio por si solos en todas las cuestiones relativas a su comercio ${ }^{25}$. He aquí que, al fin y al cabo, el Código termina por aceptar que los menores puedan ejercer el comercio.

Por otra parte, en un ámbito jurídico distinto al propio al que pertenece la noción de incapacidad para ejercer el comercio, existen una serie de prohibiciones o incompatibilidades para practicar éste. Dentro de tales prohibiciones se suelen distinguir aquellas de Derecho Público o de Derecho Privado, en razón de la naturaleza pública o privada del interés tutelado por la norma que impone la prohibición; y absolutas o relativas, según que el destinatario de la prohibición

${ }^{24}$ De hecho, la carencia de esta segunda facultad -la libre disposición de sus bienes- es lo que induce a afirmar, al menos en Derecho comparado, que el menor emancipado no puede ser empresario mercantil hasta llegar a su mayoría de edad. En efecto, buena partes de las legislaciones comparadas, entre ella la española, niegan la libre disposición de ciertos bienes a dicho menor emancipado, de modo que, no puede por sí solo tomar dinero a préstamo, gravar o enajenar bienes inmuebles y establecimientos mercantiles o industriales u objetos de extraordinario valor, necesitando para todo ello el consentimiento de sus padres y, a falta de ambos, el de su tutor. Así, ILLESCAS ORTIZ, Rafael, "El empresario mercantil individual: reglas generales" en Derecho mercantil, Vol. I, $7^{\mathrm{a}}$ edición corregida y puesta al día, dirigida por Guillermo Jiménez Sánchez, Ariel S.A., Barcelona, 2002, págs. 103 y ss.

Tal solución, a saber, la imposibilidad de que el menor emancipado no pueda ser empresario, se descarta en nuestra legislación, al tenor de lo dispuesto por el artículo 272 C. que prevé que la emancipación habilita al menor para regir su persona y bienes como si fuere mayor de edad. No obstante, existe una excepción a dicha regla general, conforme a lo señalado en el artículo 273 y 276 , que imposibilitan a que el emancipado por matrimonio, antes de haber cumplido dieciocho años, pueda administrar libremente sus bienes.

${ }^{25}$ La parte final del precepto establece que "el padre o tutor pueden continuar el comercio por cuenta del heredero menor, debiendo obtener autorización del Juez". 
no pueda ejercer ningún tipo de empresa o sólo se vea limitado a actividades o lugares previamente establecidos en la norma prohibitiva ${ }^{26}$.

Las prohibiciones absolutas de Derecho Público, se califican así en cuanto afectan a toda clase de comercio y a todo el territorio nacional, son las previstas en el artículo 11 del Código de Comercio y en algunas leyes especiales. Así, en virtud de la primera norma se prohíbe el ejercicio del comercio: a los comandantes de los puertos y empleados de las aduanas y a los quebrados que no hayan obtenido su rehabilitación.

Por lo que respecta al quebrado o comerciante declarado en quiebra, éste no se encuentra ni incapacitado ni sometido a una prohibición de comerciar sino, inhabilitado legalmente para el ejercicio del comercio ${ }^{27}$. La violación de la señalada inhabilitación comporta que "todos los actos y operaciones del quebrado y todos los pagos que hubiese realizado con posterioridad a la sentencia declaratoria de la quiebra, serán nulos por ministerio de la ley" ${ }^{28}$. Como puede inferirse de lo anterior, no existe anulabilidad de los actos constitutivos de la violación ni tampoco validez de los mismos acompañada de sanción administrativa, sino pura nulidad de los actos realizados en infracción de la inhabilitación, incluso con efecto retroactivo ${ }^{29}$.

En el caso de los reclusos que cumplen penas de presidio o prisión, las cuales llevan consigo como pena accesoria la interdicción civil por el tiempo de la condena ${ }^{30}$, éstos se encuentra imposibilitados para el ejercicio del derecho de libertad de empresa en razón de la incompatibilidad de éste con el cumplimiento de la condena.

Las probibiciones relativas de Derecho Público vienen impuestas por diversos tipos de normas. Así, en razón de la Constitución, los diputados, los funcionarios públicos de cualquier Poder del Estado, elegidos directa e indirectamente; los ministros y viceministros de Estado; los presidentes o directores de entes autónomos y gubernamentales; y los embajadores de Nicaragua en el exterior no pueden actuar como apoderados o gestores de empresas públicas o privadas, nacionales o extranjeras, en contrataciones de éstas con el Estado ${ }^{31}$.

26 ILLESCAS ORTIZ, op. cit, pág. 106.

Buena parte de los estudiosos de la materia se limitan a distinguir, únicamente, entre prohibiciones absolutas y relativas, desconociendo, por ende, la clasificación, que hemos adoptado en el texto, entre prohibiciones de Derecho Público y Privado. Con todo, nosotros creemos que tal distinción facilita la labor exegética del jurista, en razón de lo cual la hemos preferido.

27 El quebrado sufre una situación de inhabilitación que se semeja a la incapacidad, pero que no se confunde con ella. Así Sentencia del Tribunal Supremo de 30 de junio de 1978.

28 Artículo $1082 \mathrm{Cc}$.

29 SÁNCHEZ CALERO, Fernando, Instituciones de Derecho Mercantil, Volumen I, vigésima cuarta edición, revisada con la colaboración de Juan Sánchez-Calero Guilarte, McGraw Hill, Madrid, 2002, págs. 80 y s.

30 Artículo $72 \mathrm{Pn}$.

31 Artículos 130 y $135 \mathrm{Cn}$. Las mismas normas establecen que la violación de esta disposición anula las concesiones o ventajas obtenidas y causa la pérdida de la representación y el cargo. 
Ahora bien, en virtud de ley especial se prohíbe a todos los magistrados y jueces del poder judicial, actuar como consultores, apoderados o gestores de empresas públicas o privadas, nacionales o extranjeras, en contrataciones de éstas con el Estado ${ }^{32}$.

A mi juicio estas prohibiciones relativas de Derecho Público son insuficientes, ya que dejan abierta la posibilidad para que el funcionario público de que se trate pueda ejercitar la libertad de empresa, sin más limitación que en el ámbito de las contrataciones con el Estado. En otras palabras, el legislador no ha considerado siquiera la posibilidad de que el funcionario público, que a la vez es empresario, puede prevalerse de su posición para beneficiar, directa o indirectamente, la empresa de la que es titular.

Entre las prohibiciones absolutas por razón de Derecho privado, establecidas por el Código de Comercio, encontramos la del artículo 55 Cc. que probíbe a los corredores comerciar por cuenta propia, por sí, o por interpósita persona. Asimismo, la de los artículos 12 y 18 del Reglamento General sobre Bolsa de valores, Decreto $N^{\circ}$ 33-93, que establece la prohibición para ser agente de bolsa: "a los menores de 21 años, funcionarios y empleados de bancos y otras instituciones financieras, los insolventes o quebrados que no hayan sido rehabilitados, los deudores que tuvieren juicio ejecutivo pendiente por imputársele delitos contra la propiedad o falta de probidad, los que hayan sido sancionados por la superintendencia, los directores, funcionarios y empleados de otras bolsas o de la superintendencia, los que por cualquier causa sean legalmente incapaces".

Las prohibiciones relativas de Derecho privado son numerosas y pretenden, en términos generales, evitar la competencia desleal entre empresarios ubicados en diferentes grados de información o con acceso desigual a los secretos comerciales de un competidor. Estas prohibiciones afectan, por ejemplo, a los socios de las compañías colectivas y comanditarias, quienes no pueden dedicarse al mismo género de actividad que el que constituye el objeto de la sociedad ${ }^{33}$; y, con una prohibición atenuada, a los administradores de las sociedades anónimas.

En principio se admite que los extranjeros puedan adquirir la condición de empresario para ejercitar su actividad en Nicaragua. No obstante, habrá que tener en cuenta, adicionalmente, las limitaciones que derivan de la pertenencia del extranjero a alguna de las distintas categorías migratorias que regulan la Ley de Migración y la Ley de Extranjería ${ }^{34}$.

32 En idéntico sentido que el artículo anterior, "la violación de esta disposición anula las concesiones o ventajas obtenidas y causa la pérdida del cargo", todo ello de conformidad a lo prescrito por el artículo 144 numeral 10 de la LOPJ.

33 Igual prohibición rige para los gerentes o factores respecto a la actividad de su principal.

34 Sólo a manera de ilustración de nuestro dicho, puede contrastarse lo regulado, respectivamente, en los artículos 45 y 46 de la Ley de Extranjería. El primer precepto establece que los extranjeros admitidos como residentes permanentes, pueden desarrollar toda tarea o actividad remunerada o lucrativa, por cuenta propia o en relación de dependencia; por su parte, el segundo señala que los extranjeros admitidos como residentes temporales podrán desarrollar solamente las actividades tenidas en cuenta al otorgarle su residencia. 
En algunos casos la capacidad para la adquisición de la condición de empresario deberá ser resuelta, de manera previa, al tenor de lo que prescriba su propia ley nacional (tal como sucede en el caso de "los extranjeros comerciantes"), aunque el ejercicio de su actividad dentro del territorio nicaragüense se someta al régimen de Derecho interno aplicable ${ }^{35}$.

Por lo que respecta a las sociedades extranjeras que se establezcan en Nicaragua, o tengan en ella agencias o sucursales, éstas podrán ejercer el comercio, sujetándose a las prescripciones especiales del Código de Comercio en todo cuanto concierna a la creación de sus establecimientos dentro del territorio nacional, a sus operaciones mercantiles y a la jurisdicción de los tribunales de la Nación ${ }^{36}$.

Entre las señaladas prescripciones especiales destacan: "la inscripción y registro de los contratos sociales y estatutos de sociedades anónimas extranjeras que establezcan sucursales o agencias en Nicaragua, los nombramientos de gerentes o agentes y la inscripción que se bubiere hecho de dichos contratos o documentos en el Tribunal de Comercio del domicilio de las expresadas compañias"; para el resto de las sociedades extranjeras, a saber las que no sean anónimas, la inscripción y registros obligatorios que, de manera general, señala el artículo 13 del Código de Comercio; asimismo, todas las sociedades foráneas deberán mantener en el país un representante con poder generalisimo inscrito en el respectivo registro; cuando las sociedades extranjeras sean por acciones deberán publicar anualmente en el Diario Oficial (o en los otros medios autorizados por Ley), un balance que contenga con toda claridad su activo y pasivo, asi como el nombre de las personas encargadas de su administración y dirección ${ }^{37}$.

En relación a las personas jurídicas, es importante tener en cuenta que buena parte de la doctrina coincide en señalar que "el ánimo de lucro" no es una exigencia para la aplicación del derecho a la libertad de empresa ${ }^{38}$. Un ejemplo paradigmático de tal situación lo constituye el caso de las fundaciones y demás asociaciones jurídicas sin fines de lucro, ya que es perfectamente aceptado que éstas puedan alcanzar la condición de empresarios, en los casos en que desarrollan una empresa concurriendo un interés general ${ }^{39}$.

35 Todo ello se deduce de lo señalado en el artículo 9 del Cc., que prescribe que "los extranjeros comerciantes en todos los actos de comercio en que intervengan, se sujetarán a este Código y demás leyes del país", y en el artículo 339, el cual manda que las sociedades que se constituyan en país extranjero para ejercer su comercio principal en la República con la mayor parte de sus capitales levantados en ésta, o que tengan en la misma su Directorio Central y la asamblea de socios, son consideradas, para todos sus efectos, como sociedades nacionales sujetas a las disposiciones del Código de Comercio.

36 Artículo $10 \mathrm{Cc}$.

37 Artículo 337 y 13 del Cc.

38 Así ARAGÓN REYES, Libertades Económicas y Estado Social, cit., pág. 19.

39 SÁNCHEZ CALERO, Instituciones de Derecho Mercantil, cit., págs. 60 y s. 
En realidad, si bien es cierto al tenor de lo prescrito por el artículo 6 del Código de Comercio parece ser que éste únicamente consideraba que son empresarios, distintos a los individuales, las personas jurídicas que surgieran de la constitución de sociedades ${ }^{40}$, el mismo Código no prohíbe que personas jurídicas de otra naturaleza puedan adquirir esa condición. Tal es el caso de algunos entes públicos que, al gozar de autonomía y ejercitar una empresa económica, pueden llegar a adquirir la consideración de empresario ${ }^{41}$. No obstante, tal situación es más bien la excepción y no la regla, en consecuencia, lo normal será que las personas jurídico-públicas no sean sujetos activos del derecho de libertad de empresa.

Por lo que atañe a los sujetos pasivos, encontramos en primer lugar, a los poderes públicos y, en segundo término, a los particulares, quienes, de manera general, están obligados a no intervenir en el contenido y ejercicio del derecho de libertad de empresa. En efecto, el titular del derecho de libertad de empresa puede exigir, judicialmente, la eficacia directa de éste en sus relaciones con otros particulares ${ }^{42}$. En contra de tal interpretación se ha señalado, en un primer momento, que "la libertad de empresa como libertad individual es, fundamentalmente, una libertad frente al Estado y no frente a otros particulares que, por lo tanto, no están vinculados por el derecho fundamental del otro empresario". Sin embargo, el autor de dicha opinión no duda en matizar su aserto, señalando, en seguida, que "naturalmente en la medida en que se reconoce constitucionalmente (la libertad de empresa), se derivan mandatos de protección para todos los poderes públicos, de manera que el legislador está obligado a configurar el ordenamiento jurídico de manera que se proteja el derecho fundamental de cada ciudadano frente a las actuaciones de terceros que puedan lesionarlo" ${ }^{43}$. En fin, esta elucidación termina por aceptar, de manera más o menos implícita, lo que antes hemos sostenido, a saber, que tanto el Estado como los particulares son sujetos pasivos del derecho de libertad de empresa.

\subsection{Estructura tipo}

En una primera aproximación la libertad de empresa parece coincidir con la estructura propia de los denominados derechos de defensa, es decir, aquellos cuyo

40 Artículo 6: "Son comerciantes...y las sociedades mercantiles o industriales".

41 SÁNCHEZ CALERO, op. cit., pág. 60.

42 Cfr. ESCOBAR ROCA, "Derechos Fundamentales: Una aproximación General”, cit., págs. 146 y s.

43 PAZ-ARES, Cándido y ALFARO ÁGUILA-REAL, Jesús, "El Derecho a la libertad de empresa y sus límites. La Defensa de la productividad de acuerdo con las exigencias de la economía general y de la planificación" en Comentario a la Constitución Económica de España, dirección de José Luis Monereo-Pérez, Cristóbal Molina Navarrete y María Nieves Moreno Vida, Comares, Granada, 2002, pág. 365. 
objeto es preservar de la intervención del Estado un conjunto de situaciones y actuaciones que, encontrándose en peligro, se estiman como de especial importancia para el desarrollo de la persona ${ }^{44}$.

Ahora bien, sin abandonar la sede de los derechos de defensa, la libertad de empresa se encuadra, más exactamente, dentro del tipo de los derechos de libertad (que es uno de los dos tipos de derechos en que se subdividen aquéllos), a saber, los "que impiden al poder público que prohíba, dificulte o sancione el ejercicio consciente de determinadas actuaciones" ${ }^{\prime 4}$.

En el caso concreto de la libertad de empresa, las aludidas actuaciones no serán otras que aquellas que conforman su contenido y a las cuales nos referiremos en el siguiente apartado.

Sin embargo, antes de proceder en tal sentido, conviene preguntarse si, al igual que sucede con otras libertades, cabe admitir que en virtud de la libertad de empresa pueda exigirse del Estado una serie de actuaciones positivas encaminadas a garantizar los característicos intereses del aludido derecho fundamental, en otras palabras, si éste goza de una faceta prestacional ${ }^{46}$.

En nuestra opinión, es posible sostener que el derecho de libertad de empresa tiene una faceta prestacional, ya que no basta que el Estado se limite a no prohibir, no dificultar o no sancionar el ejercicio de las potestades que conforman el contenido de la libertad de empresa, antes bien, también se hace necesario que el Estado facilite la competencia efectiva entre los diferentes operadores económicos, e incluso que discipline el mercado y proteja al consumidor. Sólo de esta forma el Estado puede garantizar de forma plena el ejercicio del derecho fundamental que nos ocupa.

\subsection{Contenido}

Cada uno de los derechos fundamentales está compuesto de una serie de facultades específicas (básicamente articuladas como situaciones o acciones inmunes a injerencias externas o como exigencias de configuración de organizaciones y procedimientos o de aportación de determinadas prestaciones) que integran su contenido. Generalmente la determinación del contenido de los derechos habrá de llevarse a cabo por los distintos órganos del Estado mediante la utilización del método jurídico, "debiendo procurarse en todo caso dejar abierta la posibilidad

44 Vid. ESCOBAR ROCA, op. cit., pág. 141.

45 Vid. ESCOBAR ROCA, op. cit., ibidem.

46 Cfr. ESCOBAR ROCA, Guillermo, Estatuto de los Periodistas. Régimen normativo de la profesión y organización de las empresas de comunicación, Tecnos, Madrid, 2002, págs. 37 y s. 
de nuevos desarrollos, con el fin de impedir una inaceptable petrificación del texto constitucional" ${ }^{\prime 4}$.

Antes de proceder analizar la determinación del contenido que de la libertad de empresa han llevado a cabo los pertinentes órganos del Estado, especialmente por lo que hace al Poder Judicial a través de la jurisprudencia, nos aproximaremos a las exposiciones doctrinales del mismo, con la intención de acometer un primer acercamiento a la materia.

Para un sector de la doctrina, el contenido de la libertad de empresa se refiere a la libertad de creación de empresas y libertad de acceso al mercado, la libertad de organización del empresario y, finalmente, a la libertad de dirección de la empresa ${ }^{48}$.

El primer rasgo de la libertad de empresa es, precisamente, la libertad de emprender actividades económicas, es decir la posibilidad de libre fundación de empresas y de libre acceso al mercado de bienes y servicios. En tal sentido se afirma que la Constitución ampara todas las formas de adquirir la condición de empresario mediante la creación ex novo o la adquisición por cualquier título de poder de decisión sobre la empresa. Salvo en los sectores reservados, ello significa que cualquier persona física o jurídica que reúna los requisitos legales necesarios puede crear empresas y tiene derecho de establecimiento en cualquier sector económico, sin que quepan prohibiciones o autorizaciones puramente discrecionales de la Administración ${ }^{49}$.

Complementando lo anterior, algún autor ha dicho que a esta libertad de acceso se oponen, de forma absoluta, las reservas al sector público de recursos o servi-

47 ESCOBAR ROCA, agrega que, "como consecuencia de la consustancial indeterminación del texto constitucional, única fuente en sentido estricto de los derechos fundamentales, se admite la presencia de fuentes secundarias de éstos, que contribuyen necesariamente a determinar su contenido". Entre las señaladas fuentes secundarias se encuentran: el legislador, la jurisprudencia de la Sala Constitucional de la Corte Suprema de Justicia, la potestad reglamentaria de la Administración (aunque, eso sí, de manera muy limitada) y, finalmente, los tribunales ordinarios: (op. cit., págs. 148 y ss.).

Por otra parte, es importante no perder de vista que la noción de "contenido" del derecho fundamental, es lo que, con terminología un tanto anticuada [anclada en la nomenclatura utilizada en la Sentencia del Tribunal Constitucional, español, 11/1981, de 8 de abril (RTC 1981 \11)] se ha dado en denominar, por buena parte de la doctrina comparada, "contenido esencial" del derecho. A los efectos de la sentencia en cuestión se entiende por "contenido esencial" aquella parte del contenido de un derecho sin la cual éste pierde su peculiaridad; o, dicho de otro modo, lo que hace que sea reconocible como derecho perteneciente a un determinado tipo. Es también, aquella parte del contenido que es ineludiblemente necesaria para que el derecho permita a su titular la satisfacción de aquellos intereses para cuya constitución el derecho se otorga".

48 En tal sentido véase, entre otros, OSSENBÜHL, FRITZ, "Las libertades del empresario según la Ley Fundamental de Bonn" en Revista Española de Derecho Constitucional, traducción de Manuel Pulido Quecedo y Ulrike Oster, $\mathrm{n}^{\circ}$ 32, 1991, págs. 9 y ss.; ARIÑO ORTIZ, Gaspar, Principios Constitucionales de la Libertad de Empresa. Libertad de Comercio e Intervencionismo Administrativo, Marcial Pons - IDELCO, Madrid, 1995, págs. 85 y ss.

49 ROJO, Angel, "Actividad Económica Pública y Actividad Económica Privada en la Constitución Española" en Revista de Derecho Mercantil, n ${ }^{\circ}$ 169-170, 1983, págs.329 y s. 
cios esenciales, ya que éstas favorecen la organización de un privilegio de exclusiva. Estos privilegios no necesariamente implican un monopolio de hecho sobre la actividad, sino que, más bien, pueden dar lugar a un monopolio de derecho, en el que el Estado se reserva la titularidad de la actividad, permitiendo, sin embargo, su gestión por distintos concesionarios ${ }^{50}$.

Asimismo, continua diciendo el mismo autor, existen otras limitaciones a la libertad de acceso al mercado, como es, de una parte, la fijación de contingentes o "cupos" en sus distintas modalidades, y, de otra parte, la exigencia de condiciones subjetivas de admisión ${ }^{51}$.

Ahora bien, el segundo rasgo que distinguiría a la libertad de empresa es la libertad de organización del empresario, a saber, la posibilidad de elegir el nombre o identidad de la empresa, la forma de organización (verbigracia, sociedad anónima, sociedad de responsabilidad limitada, etc.), el emplazamiento, la constitución interna, entre otras facultades, sin más limitaciones que aquellas que estén debidamente justificadas, entre las que destacan ciertos principios de organización, publicidad y responsabilidad, en garantía de terceros, que la legislación mercantil viene configurando, de forma progresiva, como principios de orden público.

El último rasgo diferenciador es la libertad de dirección de la empresa, lo que se traduce en la libertad de tomar decisiones y de competir en un mercado libre, lo que está íntimamente vinculado con las libertades de producción, de inversión (o desinversión), de fijación de una estrategia comercial, de distribución y venta, de competencia leal y contractual.

Es importante tener presente que el artículo $104 \mathrm{Cn}$. hace referencia a ciertos límites de la libertad de empresa que afectan de manera directa a esta facultad de libertad de dirección. Nos referimos a las "limitaciones que por motivos sociales o de interés nacional impongan las leyes", no obstante, postergaremos su estudio

50 ARIÑO ORTIZ, añade que, en ambos casos, sin embargo, hay una prohibición de acceso al mercado: el monopolio de iure del Estado termina en un monopolio de facto de los distintos concesionarios, que se reparten el mercado: las zonas de suministro, las líneas de transporte, etc. Por esta razón, de acuerdo con la mejor doctrina (jurídica y económica) hay que interpretar hoy de forma muy restrictiva el artículo 105 de la Constitución Política de Nicaragua, que permite estas reservas, "subrayando la necesidad de que concurran las dos notas de esencialidad del servicio, y que éste esté llamado a ser monopolio natural”: (Principios Constitucionales de la Libertad de Empresa, cit., págs. 85 y s.).

51 ARIÑO ORTIZ, manifiesta que la exigencia de condiciones subjetivas de admisión es una característica común a todos los sectores administrativamente regulados, debido a que, efectivamente, existen supuestos en los que las condiciones técnicas o económicas de la actividad pueden justificar y exigir una especial cualificación para proteger la seguridad y estabilidad de las empresas, en garantía de los consumidores y usuarios. Estos son motivos válidos para una regulación económica, en tales sectores regulados, ya que la exigencia de condiciones subjetivas de admisión obedece, en definitiva, a la protección de la especial confianza que los ciudadanos depositan en esas empresas. Sin embargo, "por esta misma razón, la extensión de estos requisitos a actividades libres, no reguladas, es ilegítima: supone una inconstitucional restricción a la libertad de empresa": (op. cit., págs 87 y s.). 
para el apartado donde abordemos, en general, las intervenciones y límites a la libertad de empresa.

Pasando al estudio del contenido del derecho de libertad de empresa establecido por la jurisprudencia, vale decir de entrada que, como sucede respecto de buena parte de nuestros institutos jurídicos, nuestros juzgadores han rehuido el asunto. De tal forma que, como herramienta útil en este sentido, conviene echar un vistazo al Derecho comparado, especialmente al Derecho español, en donde ha habido un importante tratamiento del tema.

Vale decir que en un primer momento el Tribunal Constitucional español evitó pronunciarse sobre el tema, de modo que, en una ya clásica sentencia, el Tribunal señala que "no hay pues lugar a entrar en el análisis de qué es lo que haya de entenderse por libertad de empresa o cuál sea el contenido esencial de esta libertad, que en todo caso ha de ser compatible con el principio declarado en el apartado 1 del artículo $128^{52}$ y con las habilitaciones específicas que al legislador confieren tanto el apartado 2 de este mismo artículo ${ }^{53}$ como el apartado 1 del artículo $131^{54}$, sino sólo en la precisión de cuál sea el alcance de la reserva de ley que la garantiza" 55 .

No obstante, el voto particular de la Sentencia del Tribunal Constitucional español 37/1981 lleva a cabo una primera aproximación del contenido del derecho de libertad de empresa en los términos en los que éste se encuentra reconocido en el artículo 38 de dicha Constitución. De modo que "al reconocer la libre empresa en el marco de una economía de mercado y situarse en la línea de lo que antes llamamos constitución económica, el artículo 38 establece los parámetros del orden económico, pero no reglas jurídicas de libertad de actuación de las empresas en los concretos aspectos de la actividad económica (...). De este modo nosotros creemos que no todas las modificaciones de la concreta libertad de los empresarios se tienen que situar en el marco del artículo 38 de la Constitución, sino que se ubican en aquellos campos especiales a los que se refiera cada tipo

52 "Toda la riqueza del país en sus distintas formas, y sea cual fuese su titularidad, está subordinada al interés general".

53 "Se reconoce la iniciativa pública en la actividad económica. Mediante ley se podrá reservar al sector público recursos o servicios esenciales, especialmente en caso de monopolio y asimismo acordar la intervención de empresas cuando así lo exigiere el interés general".

54 "El Estado, mediante ley, podrá planificar la actividad económica general para atender a las necesidades colectivas, equilibrar y armonizar el desarrollo regional y sectorial y estimular el crecimiento de la renta y de la riqueza y su más justa distribución".

55 Sentencia del Tribunal Constitucional 37/1981, de 16 de noviembre. En misma línea, la Sentencia del Tribunal Constitucional 37/1987, de 26 de marzo (RTC $1987 \backslash 37$ ), declara que "el enjuiciamiento del presente motivo de inconstitucionalidad que los recurrentes reprochan a la ley andaluza no precisa que nos detengamos, con carácter previo y general, en ahondar sobre el contenido de la libertad de empresa y sobre los límites que pueden establecerse por las normas que regulen su ejercicio, cuestión que no está exenta de graves dificultades de definición a priori con carácter abstracto y de general aplicación". 
de actividad (...) si la llamada libertad de empresa es un principio justificador de la línea del orden económico, sólo puede hablarse de un "contenido esencial" de la libertad de empresa para aludir un determinado contenido, más allá del cual se adopta un sistema económico que ya no se ajusta a los parámetros constitucionalizados. Como hemos dicho más arriba, el marco constitucional permite sistemas económicos diferentes, y no es preciso que todas las actuaciones de las empresas y de los empresarios sean libres, mientras el orden económico se desenvuelva dentro de los principios de libre empresa y economía de mercado, las medidas de coerción tendentes a favorecer la libre empresa o la economía de mercado, aunque limiten la libertad de los empresarios, no alteran los términos del artículo 38".

Como puede advertirse, se dota de un carácter difuso al contenido del derecho de libertad de empresa, puesto que se trata de un marco general garantizador de un sistema de economía de mercado que no se vulnera por el hecho de establecer cualquier tipo de limitaciones o prohibiciones vinculadas con actividades empresariales $\operatorname{concretas}^{56}$. En tal sentido el Tribunal Constitucional español manifiesta que en el artículo 38 "predomina, como es patente, el carácter de garantía institucional", a partir del cual el Tribunal considera que "(...) es evidente, de una parte, que no hay "un contenido esencial" constitucionalmente garantizado de cada profesión, oficio o actividad empresarial concreta, y de la otra, que las limitaciones que a la libertad de elección de profesión u oficio o a la libertad de empresa puedan existir no resultan de ningún precepto específico, sino de una frondosa normativa, integrada en la mayor parte de los casos por normas de rango infralegal, para cuya emanación no puede aducir la Administración otra habilitación que la que se encuentra en cláusulas generales, sólo indirectamente atinentes a la materia regulada y, desde luego, no garantes de contenido esencial alguno (...) ni en el artículo 38 se reconoce el derecho a acometer cualquier empresa, sino sólo el de iniciar y sostener en libertad la actividad empresarial, cuyo ejercicio está disciplinado por normas de muy distinto orden. La regulación de las distintas (...) actividades empresariales en concreto no es, por tanto, una regulación del ejercicio de los derechos constitucionalmente garantizados en (...) el artículo 38”.

Aunque el Tribunal Constitucional español omite definir positivamente el contenido de la libertad de empresa, lo que sí resulta cierto es que el Tribunal supedita este derecho a las exigencias de la economía general y, en su caso, de la planificación, además de subordinarlo a las limitaciones derivadas de la función social de la propiedad, a las facultades de intervención que posee el Estado en la actividad económica, así como la garantía de lo que la doctrina denomina "intereses difu-

56 ARIÑO ORTIZ, Principios Constitucionales de la Libertad de Empresa, cit., pág. 95. 
sos" o "contraderechos", también reconocidos por la Constitución (entre otros, derecho a la salud, al medio ambiente, tutela de los consumidores ${ }^{57}$.

\section{4 intervenciones y límites}

Se ha dicho que la intervención sobre un derecho fundamental es aquella acción llevada a cabo por un sujeto pasivo del derecho "y que afecta negativa y significativamente a una o más de las facultades que integran su contenido". De modo que, el concepto de intervención es fundamentalmente relacional, ya que siempre estará en dependencia directa de lo que en cada caso se entienda por contenido del derecho al que la intervención se dirige ${ }^{58}$.

Las intervenciones sobre el contenido de los derechos fundamentales deben estar en cualquier caso justificadas, debiendo encontrar, necesariamente, fundamento en otra norma constitucional, la cual opera como necesario límite al derecho en cuestión. Según el Tribunal Constitucional español ${ }^{59}$, los límites de los derechos fundamentales pueden ser de dos tipos: directos (los expresamente mencionados como tales en relación con determinados derechos) e indirectos (todos los demás ${ }^{60}$.

57 ARIÑO ORTIZ, op. cit., pág. 97.

A manera de ilustración de lo arriba señalado, véase por todas la Sentencia del Tribunal Constitucional 83/1984, de 24 de julio (RTC $1984 \backslash 83$ ), donde el Tribunal deja sentado que "Nada hay, por tanto, en la Constitución que excluya la posibilidad de regular y limitar el establecimiento de oficinas de farmacia, como tampoco nada que impida prohibir que se lleve a cabo fuera de estas oficinas la dispensación al público de especialidades farmacéuticas, pues el legislador puede legítimamente considerar necesaria esta prohibición o aquella regulación para servir otras finalidades que estima deseables.

En el presente caso, el Abogado del Estado ha aducido, en apoyo de la legitimidad constitucional de la finalidad perseguida con la limitación, el mandato del artículo 43.2 de la CE y bien puede entenderse así, aunque, como es evidente, tampoco ello es necesario, pues si bien los principios rectores que contiene el Capítulo III del Título II de la Constitución se imponen necesariamente a todos los poderes públicos, nada impide que éstos se propongan otras finalidades u objetivos no enunciados allí, aunque tampoco prohibidos".

58 ESCOBAR ROCA, "Derechos Fundamentales: Una aproximación General", cit., págs. 152 y s.

59 Sentencia del Tribunal Constitucional 11/1981, de 8 de abril.

${ }^{60}$ ESCOBAR ROCA, agrega que, incluso amparándose en otra norma constitucional, las intervenciones sobre los derechos fundamentales se topan con dos nuevas barreras, que actúan como límites de los límites de los derechos: en primer término, las intervenciones sobre el contenido de los derechos del Capítulo II del Título I habrán de respetar el contenido esencial de los mismos, norma que si bien se dirige inicialmente al legislador (artículo 53.1 CE), resulta también aplicable a las intervenciones que provengan de otros sujetos; en segundo lugar, la jurisprudencia constitucional española ha venido dejando sentado que las intervenciones sobre los derechos fundamentales deberán, además, respetar el principio de proporcionalidad, el cual se concreta en tres exigencias: "a') Adecuación o idoneidad. La intervención debe resultar adecuada o idónea para el fin que se propone, que no es otro que el contenido en la norma constitucional que le dota de cobertura, bien como límite directo, bien como límite indirecto. b') Necesidad o indispensabilidad. Cuando existan dos o más medios, todos ellos constitucionalmente legítimos, para la consecución del fin que justifica la intervención, deberá optarse por el medio que menos daño cause a los derechos fundamentales. c') Ponderación o proporcionalidad en sentido estricto. Habida cuenta de que, por definición, entran en colisión dos normas constitucionales (el derecho y su límite) debe intentarse, en la medida de lo posible, una ponderación o equilibrio entre ambas, procurándose que los intereses subyacentes se respeten en lo esencial": (op. cit., págs. 153 y ss.). 
Siguiendo esta terminología podemos afirmar, apoyándonos asimismo en lo señalado por la jurisprudencia del Tribunal Supremo español, que dentro de los limites indirectos de la libertad de empresa se encuentra el principio de igualdad de oportunidades ${ }^{61}$. En la misma línea de pensamiento, el Tribunal Constitucional ha manifestado que: "No hay razón alguna para que los empresarios se encuentren en situación privilegiada respecto del resto de los ciudadanos a quienes se reconocen ámbitos de libertad concreta, pero no un ámbito de libertad total. De este modo, nosotros creemos que no todas las modificaciones de la concreta libertad de los empresarios se tienen que situar en el marco del artículo 38 de la Constitución, sino que se ubican en aquellos campos especiales a los que se refiera cada tipo de actividad"62.

Precisamente en razón de lo anterior el Tribunal Constitucional español, tal como señalamos líneas arriba, ha impuesto como límites indirectos a la libertad de empresas los derivados de la función social de la propiedad, de las facultades de intervención que posee el Estado en la actividad económica, así como las garantía de lo que la doctrina denomina "intereses difusos" o "contraderechos", también reconocidos por la Constitución.

Por otro lado, los límites directos de la libertad de empresa son, en el derecho nicaragüense, las que por motivos sociales o, en su caso, por motivos de interés nacional impongan las leyes. Resulta evidente que los motivos sociales o de interés nacional no son conceptos lo suficientemente precisos como para dejar de admitir un amplio abanico de políticas económicas en el futuro. En realidad, es difícil determinar lo que constituyen los motivos sociales, pudiendo entenderse por éstos las que se deriven del conjunto de la sociedad, o hacia los que apunta un sector mayoritario de la sociedad, a pesar de que perjudique a otro u otros. Si añadimos a tales imprecisiones las que se derivan de los motivos de interés nacional, se comprende con facilidad la indeterminación y ambigüedad del precepto.

Sin embargo, en contra de tal interpretación se arguye que dentro de la Constitución, y con toda la flexibilidad que se quiera, sólo cabe una disciplina legal que respete los límites definidos por esta clave de modelo económico constitucionalizado que es la libertad de empresa ${ }^{63}$. El reconocimiento de la libertad de empresa obliga a que tal reconocimiento sea de carácter sustantivo, es decir, que signifique algo ${ }^{64}$.

${ }^{61}$ Sentencia del Tribunal Supremo de 21 de enero de 1982.

62 Voto particular de la Sentencia del Tribunal Constitucional 37/1981, de 16 de noviembre.

63 MENÉNDEZ, Aurelio, Constitución, Sistema Económico y Derecho Mercantil, Universidad Autónoma de Madrid, Madrid, 1982, págs. 9 y ss.

64 MARTÍN-RETORTILLO, Derecho Administrativo Económico, cit., pág. 93. 
A pesar de que la Constitución no fija de manera definitiva un sistema económico, sino que, como señalamos en su oportunidad, deja en este punto un amplio margen de maniobra, lo que sí es cierto que es marca unos límites. Así, las metas hacia las que debe enrumbarse el sistema económico nicaragüense, como un elemento más del sistema socio-politico, la confluencia de otros derechos en la parcela empresarial y, en definitiva, las limitaciones que por motivos sociales o de interés nacional impongan las leyes, junto al mantenimiento irreductible de la libertad de empresa, empistan mucho hacia los ejes fundamentales del sistema económico ${ }^{65}$.

\subsection{Garantías}

Como se ha señalado acertadamente, "los derechos fundamentales pueden ser definidos como los derechos subjetivos reconocidos en la Constitución, siempre que en ésta se dote a aquéllos de las garantías típicas de toda Constitución normativa, esto es, vinculación del legislador y tutela judicial (las cursivas son nuestras)" $" 60$.

Siempre en el campo del Derecho comparado, el Tribunal Constitucional español ha manifestado que en materia de libertad de empresa la reserva de ley es la establecida en el artículo 53.1 de la Constitución ${ }^{67}$. Por lo que respecta al alcance de dicha reserva de ley, la doctrina suele interpretar que el precepto hace alusión a "Ley de Cortes", o lo que es lo mismo, que se refiere a una exigencia de forma de ley, no de rango ${ }^{68}$, lo que descartaría el decreto-ley como cauce normativo en la materia ${ }^{69}$.

En mi opinión, a partir de la lectura de las normas contenidas en el Capítulo I, del Título VI del Texto Constitucional Nicaragüense, es posible llegar a una conclusión similar, a saber, que el constituyente se ha inclinado por conceder a la libertad de empresa la reserva de ley "parlamentaria".

${ }^{65}$ En similar sentido véase CAZORLA PRIETO, Luis María, quien manifiesta que, si recordamos de manera particular el artículo 128.2 de la Constitución española (reconocimiento de la iniciativa pública en el campo económico en pie de igualdad con la privada) -que guarda muchas similitudes con el artículo 99 de nuestra Constitución- y lo agregamos a lo arriba señalado, se puede concluir que, omitiendo calificaciones doctrinales, nuestro sistema económico es de compatibilidad de la iniciativa pública y la privada. A la vez que esta última puede sufrir limitaciones concretas en aras a otros derechos consagrados constitucionalmente y a las limitaciones que por motivos sociales o de interés nacional impongan las leyes: ("Artículo 38" en Comentarios a la Constitución, tercera edición ampliada, dirigida por Fernando Garrido Falla, Civitas, Madrid, 2001, págs. 838 y s.).

${ }^{66}$ ESCOBAR ROCA, "Derechos Fundamentales: Una aproximación General”, cit., pág. 133.

67 En tal sentido véase Sentencia del Tribunal Constitucional 37/1981, de 16 de noviembre.

Artículo 53.1 CE: "Los derechos y libertades reconocidos en el capítulo segundo del presente título vinculan a todos los poderes públicos. Sólo por ley, que en todo caso deberá respetar su contenido esencial, podrá regularse el ejercicio de tales derechos y libertades, que se tutelarán de acuerdo con lo previsto en el artículo 161.1.a)".

${ }_{68}$ PECES-BARBA MARTÍNEZ, La Constitución española de 1978, Fernando Torres editor, Valencia, 1981, págs. 106 y ss.

${ }^{69}$ CAZORLA PRIETO, “Artículo 38”, cit., pág. 841. 
De manera general, la consideración de la libertad de empresa como derecho fundamental conlleva que su titular ostente un estatus jurídicamente protegible por los Tribunales de Justicia, frente a posibles actuaciones de los distintos Poderes públicos y de los particulares que pudieran suprimirla, modificarla o reducirla. De tal forma que, su violación da lugar a la interposición del correspondiente recurso de inconstitucionalidad o, en su caso, el de Amparo.

Asociado a estas garantías generales, algunos ordenamientos jurídicos han establecido específicas garantías para salvaguardar la integridad del derecho de libertad de empresa. Entre éstas destaca la facultad del titular del derecho en cuestión para accionar el conjunto de normas que se ha dado en denominar "Derecho de la Competencia". Empero, antes de proceder a su examen, nos detendremos brevemente para realizar un par de precisiones impostergables para el cabal entendimiento de las conexiones existentes entre el Derecho de la Competencia y la libertad de empresa.

Como se ha afirmado correctamente, la "competencia" es el modo natural en que se manifiesta la libertad de empresa, erigiéndose, en consecuencia, en la base del sistema capitalista. Por ello se ha sostenido que "libertad y competencia se han hecho términos sinónimos" ${ }^{70}$.

Dicho en otras palabras, la existencia de competencia en el mercado es el corolario de la libertad de empresa. De tal forma que, los poderes públicos están obligados, de modo ineludible, a defender la competencia, debiendo fortalecer, a tal efecto, los mecanismos del mercado y procurando impedir que los agentes u operadores económicos desvirtúen el sistema mediante la realización de prácticas anticompetitivas ${ }^{71}$.

Así, la competencia es instalada por el Derecho mediante dos conjuntos de normas destinadas a la defensa de sus dos facetas más significativas: el derecho de la libre competencia y el derecho de la competencia leal (o sistema regulador de la competencia desleal) ${ }^{72}$.

El derecho de la libre competencia (también conocido como legislación de defensa de la competencia o legislación antitrust) persigue la represión de las prácticas empresariales que restringen o eliminan la competencia en el mercado o en

70 GARRIGUES, Joaquín, Curso de Derecho Mercantil, séptima edición revisada con la colaboración de Alberto Bercovitz, imprenta Aguirre, Madrid, 1976, pág. 223.

71 En tal sentido véase la Sentencia del Tribunal Constitucional español de 1 de julio de 1986. ALONSO SOTO, Ricardo, "Derecho de la competencia (I). Introducción y Derecho Comunitario" en Uría-Menéndez, Curso de Derecho Mercantil, Tomo I, Civitas, Madrid, 1999, pág. 243.

72 RUIZ DE VELASCO, Adolfo, Manual de Derecho Mercantil, Universidad Pontificia de Comillas, Madrid, 1999, págs. 89 y s. 
uno de sus segmentos. Por su parte, el derecho de la competencia leal combate conductas empresariales que sin producir restricciones a la libertad las introducen en las prestaciones, tendiendo a evitar, de esa forma, un triunfo empresarial fundamentado en prácticas desleales ${ }^{73}$.

Llevando a cabo un análisis muy elemental, que forzosamente tenemos que llevar a cabo en Derecho comparado, a falta de una legislación propia de la materia, podemos decir que al tenor de lo prescrito en los artículos 1 y 6 de la Ley de Defensa de la Competencia española, se prohíben aquellas prácticas que, siendo efectivamente prácticas competitivas, resultan prohibidas en su ejecución porque o bien impiden, falsean o limitan la libre competencia en todo o en parte del mercado nacional, o bien constituyen un abuso de la posición de dominio que en el mercado ostenta quien las lleva a cabo. Así, de lo anterior se infiere que la Ley concibe dos principales categorías de prácticas prohibidas, a saber, las prácticas concertadas o colusorias y las prácticas abusivas ${ }^{74}$.

También conviene tener en cuenta que la norma española prevé, en su artículo 2, la exclusión de la sumisión a su imperio de ciertas prácticas, que constituyen restricciones a la libre competencia, resultables de la aplicación de una Ley. Dicho de otra forma, siempre que una norma con rango de Ley permita una actuación administrativa a cuyo amparo se realice una práctica restrictiva de la competencia calificable a priori como prohibida, tal práctica no quedará sometida a las sanciones previstas por la Ley 16/1989 y su realización no podrá ser combatida ${ }^{75}$.

El precepto regula, además, una serie de conductas autorizables, entendiéndose por éstas las que incurriendo, por su naturaleza o contenido, en alguna de las prohibiciones establecidas, y sin ser calificables como autorizadas, resultan susceptibles de autorización por los órganos administrativos competentes, atendiendo a razones de superior interés económico o a su escasa importancia económica. Obviamente, tras su autorización la práctica autorizable se convierte en práctica autorizada ${ }^{76}$.

${ }_{73}$ Por si no hubiera quedado ya suficientemente evidenciado, traemos a colación aquí el comentario de ILLESCAS ORTIZ, Rafael, quien afirma que la generalidad de la doctrina entiende que la defensa de la competencia en las dos facetas expuestas constituye un postulado constitucional consagrado en su articulado: ("Derecho de la Competencia: la libre competencia" en Derecho mercantil, Vol. I, $7^{\mathrm{a}}$ edición corregida y puesta al día, dirigida por Guillermo Jiménez Sánchez, Ariel S.A., Barcelona, 2002, pág. 658).

74 También se suele afirmar que las prácticas prohibidas pueden ser calificadas, en segundo término y en atención a los sujetos que en su concepción y ejecución intervienen, como prácticas plurilaterales o unilaterales. Las plurilaterales (aquellas en las que interviene más de un sujeto) suelen coincidir con las prácticas colusorias y las de concentración de empresas. Las unilaterales (en las que sólo interviene un empresario con peso suficiente como para influir en la situación imperante en el mercado) suelen ser ordinariamente prácticas abusivas. ILLESCAS ORTIZ, Derecho mercantil, cit., págs. 659 y ss.

75 URÍA, Rodrigo, Derecho Mercantil, vigésimo octava edición, revisada con la colaboración de María Luisa Aparicio, Marcial Pons, Madrid, 2002, pág. 141.

76 ILLESCAS ORTIZ, Derecho mercantil, cit., pág. 665. 
Estas conductas autorizables pueden ser de dos tipos: las singulares (reguladas en el artículo 4), son aquellas que pese a reunir las condiciones de las prácticas prohibidas son autorizadas de modo específico y directo, para cada caso concreto, por el Tribunal de Defensa de la Competencia; y las conductas autorizadas mediante una exención por categoría (artículo 5), las que forman parte, en virtud de sus características, de una determinada clase o categoría de acuerdos, decisiones o conductas cuya realización, no obstante ser restrictiva, es autorizada de modo general por el Gobierno mediante la promulgación de un denominado Reglamento de exención ${ }^{77}$.

$\mathrm{Al}$ mismo tiempo, la Ley española contiene normas de control de las concentraciones económicas y de control público de ayudas públicas. Por lo que concierne al control general de la libertad de competencia, está es vigilada por una pluralidad de organismos administrativos: El Tribunal de Defensa de la Competencia, el Servicio de Defensa de la Competencia y el Registro de Defensa de la Competencia $^{78}$.

El Tribunal de Defensa de la Competencia, creado por el artículo 20 de la Ley, es el principal órgano encargado de la aplicación de la Ley, teniendo como primordial función la de declarar que conductas o prácticas están o no prohibidas y, en consecuencia, son nulas o no, y cuáles podrán ser objeto de autorización (sin perjuicio de que, además, adopta acuerdos, emite informes, entre otras funciones). Por tal razón se afirma que se trata de un órgano jurisdiccional de naturaleza especial, pues sus resoluciones definitivas -como si se tratara de un simple acto de la Administración Pública que agota la vía administrativa- son susceptibles de revisión judicial en vía contencioso-administrativa ${ }^{79}$.

Por su parte, el Servicio de Defensa de la Competencia es un órgano administrativo al servicio de la aplicación de la Ley de Defensa de la Competencia, sus principales funciones son dos: servir de instrumento administrativo de actuación al Tribunal de Defensa de la Competencia y al Ministerio de Economía y, asimismo, es el encargado de la llevanza del Registro de Defensa de la Competencia. Este último es un registro público en el que se inscriben los acuerdos, decisiones, recomendaciones y prácticas que el Tribunal haya autorizado y los que haya declarado prohibidos total o parcialmente. También se inscribirán las operaciones de concentración de empresas sometidas a control público ${ }^{80}$.

77 SÁNCHEZ CALERO, Instituciones de Derecho Mercantil, cit., págs. 123 y s.

78 FERNÁNDEZ, José Luis, Elementos de Derecho Mercantil, cuarta edición actualizada, ediciones Deusto S.A., Bilbao, 2000, págs. 96 y ss.

79 SÁNCHEZ CALERO, Instituciones de Derecho Mercantil, cit., pág. 127.

${ }^{80}$ URÍA, Derecho Mercantil, cit., págs. 144 y s. 
El conjunto de normas que hemos denominado derecho de competencia leal se encuentra contenido, en el ordenamiento español, en dos preceptos principales. En primer lugar, la Ley 3/1991, de 10 de enero, de Competencia Desleal, la cual consagra el derecho general de la competencia desleal en España. En segundo término, la Ley 34/1988, de 11 de noviembre de 1988, General de Publicidad. Este último texto, a diferencia del anterior, sólo posee un valor sectorial, ya que únicamente resulta aplicable a las deslealtades empresariales puestas en práctica a través de la actividad publicitaria ${ }^{81}$.

De manera sintética podemos decir que la Ley 3/1991 establece, en un primer momento, un conjunto de disposiciones generales relativas a su campo de aplicación; acto seguido prescribe una prohibición de carácter general para cualquier acto o situación de deslealtad competitiva que en el mercado pueda existir; posteriormente enuncia actos concretos de competencia desleal cuya sanción es consagrada y, finalmente, prevé una disciplina amplia y no excesivamente afortunada de los aspectos procesales de la deslealtad competitiva, acciones que podrán ejercitar los perjudicados contra los causantes de la deslealtad, así como las vías procesales idóneas al efecto ${ }^{82}$.

\section{BIBLIOGRAFÍA}

- ALONSO SOTO, Ricardo, "Derecho de la competencia (I). Introducción y Derecho Comunitario" en Uría-Menéndez, Curso de Derecho Mercantil, Tomo I, Civitas, Madrid, 1999.

- ARAGÓN REYES, Manuel, Libertades Económicas y Estado Social, McGraw-Hill, Madrid, 1995.

- BASSOLS COMA, Martín, Constitución y Sistema Económico, segunda edición, Tecnos, Madrid, 1988.

- BREWER-CARÍAS, Allan R., "Reflexiones sobre la constitución económica" en Estudios sobre la Constitución Española. Homenaje al Profesor Eduardo García de Enterría, Tomo V, coordinación y presentación por Sebastián Martín-Retortillo, Civitas, Madrid, 1991.

- DE LOJENDIO, Ignacio María, "Derecho Constitucional Económico" en Constitución y Economía. La Ordenación del Sistema Económico en las Constituciones Occidentales, coordinado por Luis Sánchez Agesta, Editorial Revista de Derecho Privado - Editoriales de Derecho Reunidas, Madrid, 1977.

${ }^{81}$ FERNÁNDEZ, Elementos de Derecho Mercantil, cit., págs. 101 y ss.

${ }^{82}$ SÁNCHEZ CALERO, Instituciones de Derecho Mercantil, cit., págs. 130 y ss. 
- ESCOBAR ROCA, Guillermo, "Derechos Fundamentales: Una aproximación General" en Anuario de la Facultad de Derecho de Alcalá de Henares. Curso 1998-1999, número extraordinario en homenaje al Prof. Don Luis García San Miguel, Volumen VIII, Universidad de Alcalá de Henares, Alcalá de Henares, 2000.

- ESCOBAR ROCA, Guillermo, Estatuto de los Periodistas. Régimen normativo de la profesión y organización de las empresas de comunicación, Tecnos, Madrid, 2002.

- FERNÁNDEZ, José Luis, Elementos de Derecho Mercantil, cuarta edición actualizada, ediciones Deusto S.A., Bilbao, 2000.

- GARCÍA-PELAYO, Manuel, "Consideraciones sobre las cláusulas económicas de la Constitución" en Estudios sobre la Constitución española de 1978, edición preparada por Manuel Ramírez, Libros Pórtico, Zaragoza, 1979.

- GARRIGUES, Joaquín, Curso de Dere MENÉNDEZ, Aurelio, Constitución, Sistema Económico y Derecho Mercantil, Universidad Autónoma de Madrid, Madrid, 1982.

- ORTIZ, Gaspar, Principios Constitucionales de la Libertad de Empresa. Libertad de Comercio e Intervencionismo Administrativo, Marcial Pons - IDELCO, Madrid, 1995.

- OSSENBÜHL, FRITZ, "Las libertades del empresario según la Ley Fundamental de Bonn" en Revista Española de Derecho Constitucional, traducción de Manuel Pulido Quecedo y Ulrike Oster, nº 32, 1991.

- PAZ-ARES, Cándido y ALFARO ÁGUILA-REAL, Jesús, "El Derecho a la libertad de empresa y sus límites. La Defensa de la productividad de acuerdo con las exigencias de la economía general y de la planificación" en Comentario a la Constitución Económica de España, dirección de José Luis Monereo-Pérez, Cristóbal Molina Navarrete y María Nieves Moreno Vida, Comares, Granada, 2002.

- PECES-BARBA MARTÍNEZ, La Constitución española de 1978, Fernando Torres editor, Valencia, 1981.

- ROJO, Angel, “Actividad Económica Pública y Actividad Económica Privada en la Constitución Española" en Revista de Derecho Mercantil, nº 169-170, 1983.

- RUIZ DE VELASCO, Adolfo, Manual de Derecho Mercantil, Universidad Pontificia de Comillas, Madrid, 1999.

- SÁNCHEZ CALERO, Fernando, Instituciones de Derecho Mercantil, Volumen I, vigésima cuarta edición, revisada con la colaboración de Juan Sánchez-Calero Guilarte, McGraw Hill, Madrid, 2002.

- URÍA, Rodrigo, Derecho Mercantil, vigésimo octava edición, revisada con la colaboración de María Luisa Aparicio, Marcial Pons, Madrid, 2002. 